\title{
RELACIÓN IGLESIA-ESTADO Y MASCULINIDAD HEGEMÓNICA EN LA RESOLUCION 99: UN ANÁLISIS CRÍTICO DEL DISCURSO ${ }^{1}$
}

\author{
Iván de Jesús Rosa ${ }^{2}$ \\ Ángel L. Crespo Vázquez ${ }^{3}$
}

\section{Resumen}

El artículo presenta un análisis crítico del discurso de las transcripciones de las sesiones legislativas y las ponencias presentadas en torno a la Resolución Concurrente del Senado de Puerto Rico \#99 de 2007, que pretendía elevar a rango constitucional el matrimonio heterosexual y prohibir que se le reconocieran derechos similares a los del matrimonio a cualquier otro tipo de uniones familiares. El principal propósito del estudio fue identificar las ideologías que guiaron a los diversos actores sociales en torno a este evento. El enfoque teórico utilizado en el estudio fue la sexualidad desde el poder (Foucault, 2007). Como metodología se utilizó el análisis crítico del discurso expuesto por Fairclough (2005) y Fairclough y Wodak (1997) citados en Lucca y Berríos (2009). El análisis se realizó partiendo de las siguientes dos categorías temáticas: Relación Iglesia-Estado y Masculinidad Hegemónica.

Descriptores: Resolución 99, Relación Iglesia-Estado, Masculinidad Hegemónica, Análisis Crítico del Discurso, Trabajo Social, Política Social.

\section{Abstract}

The article presents a critical analysis of the discourse of the transcripts of the legislative session and the papers presented about the Concurrent Resolution of the Puerto Rico Senate \#99 of 2007, which pretended to raise up to constitutional level the heterosexual marriage and prohibit similar rights to any other kind of family unions.

\footnotetext{
${ }^{1}$ Artículo basado en:

Crespo Vázquez, A. L; De Jesús Rosa, I. \& Martí Ramírez de Arellano, Y. M. (2009). Resolución 99, un conflicto para la historia: Análisis crítico del discurso de las transcripciones de las sesiones legislativas y de las ponencias presentadas por grupos pro derechos civiles y grupos religiosos, en torno a la Resolución Concurrente del Senado \#99 de 2007, en San Juan, a mayo de 2009. Tesis de maestría no publicada. Universidad de Puerto Rico, Recinto de Río Piedras.

${ }^{2}$ Trabajador Social Escolar del Departamento de Educación.

${ }^{3}$ Trabajador Social de la AdministraciónDde Servicios de Salud Mental y Contra laAdicción.
} 
The main purpose of the study was to identify the ideologies that guided the various socialactors in this event. The theoretical approach used in the study was the sexuality from a power perspective (Foucault, 2007). As methodology we utilized the critical analysis of the discourse exposed by Fairclough (2005) and Fairclough \& Wodak (1997) cited in Lucca \& Berríos (2009). The analysis was conducted on the basis of the following two thematic categories: Relationship between Church-State and Hegemonic Masculinity.

Keywords: Resolution 99, Relationship between Church-State, Hegemonic Masculinity, Critical Analysis of the Discourse, Social Work, Social Policy.

\section{Introducción}

Entre los años 2007 al 2008, se conjugaron diversos factores que propiciaron se desarrollara una lucha protagonizada por varios sectores influyentes de nuestra sociedad. El Borrador del Nuevo Código Civil, presentado por la Comisión Legislativa para la Revisión y Reforma del actual código civil, provocó respuestas de diversos grupos ante el reclamo que se hacía de extensión de derechos hacia las catalogadas "uniones de hecho". Se proponía considerar como unión de hecho "la constituida por dos personas que, sin estar casadas entre sí, conviven como pareja afectiva de manera voluntaria, estable, pública y continua, durante un plazo no menor de tres (3) años." (Comisión Conjunta Permanente para la Revisión y Reforma del Código Civil, 2003). En respuesta al estatuto presentado, se generó la propuesta de enmienda constitucional conocida como la Resolución Concurrente del Senado \#99 de 2007, que procuraba "enmendar el artículo II de la constitución de Puerto Rico, a los fines de incluir en la sección 20 el deber de elevar a rango constitucional el matrimonio, constituido sólo por la unión legal entre un hombre y una mujer, con capacidad legal, en conformidad con su sexo original de nacimiento" (Senado de Puerto Rico, Res. 99, 2007). De esta forma se aseguraría que el actual concepto de matrimonio no pudiera ser alterado fácilmente por posteriores legislaturas o por interpretaciones de la judicatura. Ésta Resolución leía como sigue:

El matrimonio es una institución civil, que se constituirá sólo por la unión legal entre un hombre y una mujer en conformidad con su sexo original de nacimiento. Ninguna otra unión, independientemente de su nombre, denominación, lugar de procedencia, jurisdicción o similitud con el matrimonio, será reconocida o validada como un matrimonio.

En la exposición de motivos de esta medida se planteó que "la familia tiene la función primordial de promover el bien de todos en nuestra sociedad"; que el Estado "debe promover y estimular la familia constituida por el matrimonio entre un hombre y una mujer en conformidad con su sexo de nacimiento"; y que "la familia, cimentada en la 
unión matrimonial monogámica entre el hombre y la mujer es un bien necesario e imprescindible, que tiene un valor intrínseco en derecho y justicia, a ser reconocido, protegido y promovido por el Estado para la prolongación responsable del género humano" (Senado de Puerto Rico, Res. 99, 2007, p. 2).

Organizaciones profesionales establecieron que la aprobación de la Resolución 99 hubiera tenido serias implicaciones en la vida de diversos sectores dentro de la sociedad puertorriqueña. Entre los sectores que más negativamente se verían afectados se encuentran "familias con un solo padre o madre, abuelos criando nietos, hijos viviendo con padrastros o madrastras, familias sustitutas, familias de padres del mismo sexo e inclusive hogares grupales" (Sociedad Puertorriqueña de Psiquiatría, 2008, p. 2).

Considerando los diversos problemas sociales que se hubieran podido desencadenar ante las enmiendas propuestas al marco constitucional del país, la pregunta medular que condujo a este estudio fue: ¿Cuáles fueron las ideologías que fundamentaron los posicionamientos de los grupos pro derechos civiles, organizaciones profesionales, agencias de gobierno, grupos religiosos y de los legisladores(as), en torno a la Resolución Concurrente del Senado \#99 de 2007?

Para esto, partimos de la definición del término ideología planteado por Chatterjee (1996), siendo la manera más simple de explicarla, según la autora, como la legitimación y naturalización de las relaciones sociales. Chatterjee (1996) plantea que: "estas relaciones pueden ser entre géneros, entre generaciones, entre empleadores y empleados, entre co-trabajadores... entre un profesional y un cliente; o entre el gobernador y los gobernados. Además, la relación puede ser igualitaria o jerárquica; un medio para alcanzar un fin o un fin en sí mismo" (p. 87, traducido por los autores).

\section{Marco Teórico}

Este estudio se enmarca en postulados del autor Michel Foucault (2007) dentro de la corriente teórica postmoderna. Este filósofo enuncia la relación entre poder, saber y placer; elabora el concepto de poder en términos de discursos y aborda la sexualidad como construcción social. Foucault (2007) también explica cómo se construye la identidad sexual, la sexualidad patológica y cómo surge el discurso negativo o perverso acerca de la misma. Para este autor los discursos estructuran las relaciones entre las personas y son reflejo de los posicionamientos ideológicos que los sustentan.

Según Foucault (2007) "todavía a comienzos del siglo XVII... las prácticas no buscaban el secreto... y las cosas se decían sin demasiado disfraz; se tenía una tolerante familiaridad con lo ilícito" (p. 9). Estas expresiones delinean que los significados e ideas que se tienen actualmente sobre la sexualidad resultan de la construcción social que emana en un momento histórico determinado. Ubica al lector en dicho contexto histórico cuando dice que el "siglo XVII: sería el comienzo de una edad de represión, 
propia de las sociedades llamadas burguesas, y de las que quizá no estaríamos completamente liberados" (Foucault, 2007, p. 25). Se evidencia que la represión de la sexualidad no ha existido desde siempre, sino que su aparición en la historia de la humanidad es identificable. La represión sexual tiene explicación histórica y las sociedades actuales posiblemente no estén totalmente liberadas de las ideas sobre la sexualidad que caracterizan el orden burgués hipócrita, como le llama Foucault. La represión sexual llegó con la modernidad desde la edad clásica, consolidada en el orden burgués.

Estos discursos se institucionalizan a través del aparato legal estatal, pero también se presentan en la institución familiar, en la iglesia, en el mercado y en otras formas de relaciones sociales. Se institucionalizan porque los grupos dominantes son los que elaboran las políticas del Estado. El discurso de algunas políticas se asienta en un sistema de ideas y valores de la clase dominante, fundamentándose en la visión ideológica de la cual parten.

Foucault (2007) plantea que la noción de 'sexualidad' es reciente, puesto que este concepto emerge en el siglo XIX. Afirma que:

... se ha establecido el uso de la palabra en relación con otros fenómenos: el desarrollo de campos de conocimientos diversos... el establecimiento de un conjunto de reglas y normas... que se apoyan en instituciones religiosas, judiciales, pedagógicas, médicas; cambios... en la manera en que los individuos se ven llevados a dar sentido y valor a su conducta, a sus deberes, a sus placeres, a sus sentimientos y sensaciones, a sus sueños. Se trataba... de ver cómo, en las sociedades occidentales modernas, se había ido conformando una 'experiencia', por la que los individuos iban reconociéndose como sujetos de una "sexualidad", abierta a dominios de conocimientos muy diversos y articulada con un sistema de reglas y de restricciones (Foucault, 2003, p. 7).

Desde que el ser humano apalabra el comportamiento, con el vocablo sexualidad, le atribuye significaciones que pasan a ser normativas sociales institucionalizadas. He aquí la relación entre saber, poder y placer, ya que con la ciencia moderna positivista y todas sus especialidades, desde la medicina hasta la psicología, se construye la noción de sexualidad.

La ciencia, la iglesia y el estado como instituciones propias del orden burgués demandaron la gobernabilidad de los sujetos para la dominación y el control social. Asimismo, las personas internalizaron, por medio de procesos de aprendizaje, en dichas instituciones, los sentidos sobre la sexualidad que por un lado la iglesia demoniza, por otro la ciencia patologiza y el estado criminaliza cuando no cumple con los estándares 
establecidos. Por lo tanto, el sujeto aprende sus deberes, reprime sus placeres y controla sus sentimientos para no ser etiquetado y rechazado socialmente. Foucalt (2007) trae a colación el elemento de la trasgresión de las normativas sociales mencionando que para liberarse de la represión sexual... haría falta la trasgresión de las leyes, la anulación de la prohibiciones, una irrupción de la palabra, una restitución del placer a lo real y toda una nueva economía en los mecanismos del poder, pues el menor fragmento de verdad está sujeto a condición política (p.11).

O’Brien (1999), haciendo referencia a Foucault, expone que en los últimos siglos el control sobre el sexo se ha ido incrementando como objeto de lo que él denomina BioPoder, entendido esto cómo la administración de la vida. El Bio-Poder se ha desarrollado en dos polos principales, el primero es el 'poder disciplinario', el cual opera en el cuerpo humano como si fuera un tipo de máquina, intentando optimizar sus capacidades, eficiencia, utilidad y docilidad política. El segundo polo del Bio-Poder es la 'regulación de la población', esta forma de poder se centra en los procesos biológicos como los nacimientos, mortalidad y probabilidades de vida; sus instrumentos han incluido intervenciones económicas y campañas de salud pública, entre otros. Es mediante estos mecanismos que se pretende convertir la vida en objeto administrable por parte del poder.

\section{Diseño Metodológico}

Para esta investigación se recopilaron todas las ponencias presentadas ante las comisiones legislativas que atendieron la Resolución 99. Luego se optó por utilizar sólo aquellas ponencias presentadas por agencias de gobierno, organizaciones religiosas, pro-derechos civiles, profesionales y/o religiosas y no aquellas presentadas por personas en su carácter individual, quedando entonces 24 ponencias. Se determinó utilizar también las transcripciones de las sesiones legislativas para recoger los discursos esbozados por los legisladores (as) respecto a nuestro tema de estudio.

El método de investigación para analizar las ponencias fue el análisis crítico del discurso expuesto por Fairclough (2005) y Fairclough y Wodak (1997), citado en Lucca y Berrios (2009). En el análisis crítico del discurso se plantea que "las prácticas discursivas pueden tener efectos ideológicos de peso en la medida en que ayudan a producir y a reproducir relaciones de poder desiguales entre sexos, las clases sociales y los grupos étnicos" (Lucca y Berrios, 2009, p.267). Estos autores, además señalan que el análisis del discurso

...se materializa cuando se examina de qué manera construye en lenguaje la realidad social, al tratar de entender mejor la vida social y las interacciones humanas, a través del análisis de la comunicación como textos sociales. Es por esta razón que el análisis del discurso es primordialmente constructivista (Lucca y Berrios, 2009, p.268). 
Para el análisis inicial de las ponencias y transcripciones legislativas se realizaron varias lecturas de las mismas por cada uno de los investigadores de manera individual y sin contar con categorías temáticas preestablecidas. Mientras realizábamos la lectura de los documentos identificamos frases discursivas esbozadas por los actores y actrices sociales que se utilizarían para el análisis y les asignamos varias categorías temáticas. Luego en discusión grupal se estipularon las categorizaciones finales en consenso. Estas fueron: Relación Iglesia-Estado y Masculinidad Hegemónica ${ }^{4}$, las cuales se utilizaron para realizar el análisis crítico del discurso.

\section{Hallazgos:}

Para el análisis crítico del discurso, se hace especial énfasis en la identificación del contenido ideológico de los discursos y en los efectos concretos que los mismos tienen dentro de la sociedad puertorriqueña. En la figura 1 se presentar los lineamientos discursivos de los favorecedores de la Resolución 99 desde la categoría temática Relación iglesia-estado.

Figura \#1

Relación Iglesia - Estado

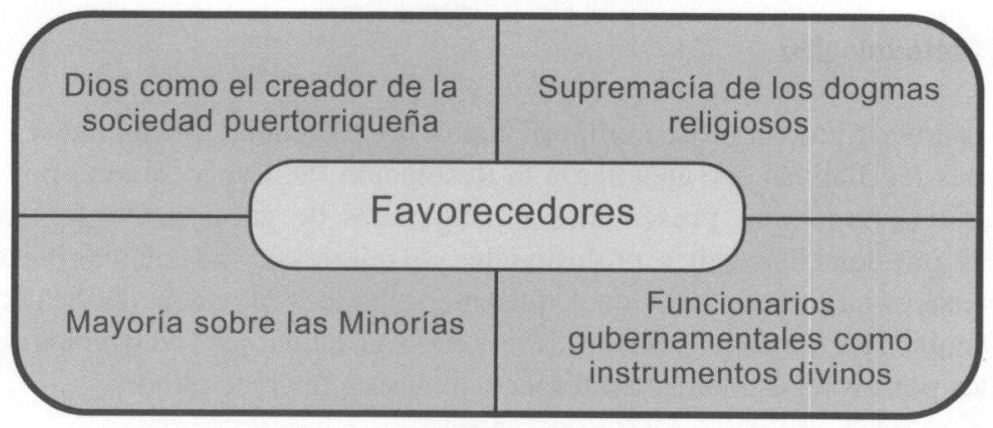

Muchos de los deponentes caracterizaron a algunos de los protagonistas de nuestra historia política como enviados de Dios, con el propósito de instaurar leyes que van acorde con su plan divino. Este argumento lleva a visualizar el Estado como un espacio más donde Dios debe actuar y hacer valer sus preceptos. A partir de este argumento se entendería entonces que, si desde el establecimiento de nuestro sistema político Dios dispuso lo que serían nuestras costumbres y manera de vida, nuestra continuación como pueblo estará intrínsecamente ligada a continuar cumpliendo con los preceptos impuestos por Él.

\footnotetext{
${ }^{4} \mathrm{La}$ masculinidad hegemónica establece la heteronormatividad que se impone sobre otras masculinidades y mantiene al margen a las personas que no encajan en sus estándares sociales. (Ramírez y García, 2002).
} 
Los sectores favorecedores también apalabraron la concepción del Dios histórico que fundó al pueblo puertorriqueño sobre unos valores infalibles, los cuales deben ser reforzados mediante la elevación a rango constitucional del matrimonio heterosexual. Esto, a riesgo de caer en una gran debacle moral. Este tipo de posicionamientos partió exclusivamente de una interpretación religiosa de la historia, validando una visión del mundo y de la historia humana centrada en Dios y obviando interpretaciones históricas de carácter secular.

Una de las consecuencias ideológicas de este discurso es que posicionaba a la doctrina cristiana por encima de otros dogmas religiosos y no religiosos, lo cual podría resultar en una degradación, tanto social como legal, de cualquier otra creencia diferente. Validando así la superioridad del cristianismo ante cualquier otra creencia. Se pudo apreciar cómo se establecía una relación directa entre lo que indican las religiones cristianas y qué y cómo se debía legislar. Lo que establecieran las iglesias debía estar endosado por el Estado, con el propósito de validar dichos estilos de vida, descartando o limitando aquellos que se contrapongan. Se legitimaba así la visión cristiana de la familia y se penaliza cualquier otro tipo de unión. Se hacía referencia constante a Puerto Rico como un pueblo de valores cristianos, obviando la diversidad de la cultura puertorriqueña y que hay personas que se rigen por códigos de valores que no se fundamentan en el cristianismo. Veamos un ejemplo de esto:

...confiamos en quien todo lo puede que sea el que nos dirija, a que no tengamos temor a ninguna persona y a ninguna organización; que solamente nos tiemblen las rodillas al no actuar, según la voluntad del que todo lo puede y que nos ha traído a cada uno de nosotros a estar aquí a defender los valores que nos han distinguido como pueblo (Senado de P.R., Transcripción Legislativa, Arce Ferrer, 2007, p. 5).

Las organizaciones favorecedoras validaban el que se elevara el matrimonio heterosexual a nivel constitucional aludiendo a su alegada supremacía numérica versus la pequeñez de los sectores opositores. Asumieron el discurso del poder de las mayorías sobre las minorías, justificando que en un país democrático deberían ser ellos como mayoría los que impongan el orden moral que rija a la sociedad. Se les señala constantemente a los opositores de la Resolución 99 como un "grupito minúsculo", intentando invalidar así sus planteamientos y asumiendo que al los opositores ser (según ellos) minoría, se debían amoldar a lo que la mayoría decida, ya que se visualizaban a sí mismos como los representantes del sentir del pueblo puertorriqueño. De esta forma se logra justificar la exclusión del grupo "minúsculo" de la igualdad ante las leyes.

Se menciona constantemente que la función de los legisladores era garantizar la continuidad del plan divino, por lo cual debían entregar sus prerrogativas a los intereses 
de las iglesias cristianas, obviando que desde su puesto político están llamados constitucionalmente a representar a todos sus constituyentes y no sólo a personas de creencias cristianas. Analizando la percepción de legisladores, sobre el concepto de separación de Iglesia y Estado, encontramos que visualizan al Estado y a sí mismos (o así mismas) como funcionarios estatales con la misión de propagar la obra de la Iglesia a través de sus ejecutorias. En esta argumentación se visualiza cómo los legisladores y legisladoras entienden que su poder emana tanto del Estado Libre Asociado como del Dios Omnipotente. Para ellos y ellas no existe ningún tipo de separación entre su función en la Legislatura y sus creencias religiosas ya que emanan de un principio unificador: Dios y el Estado como uno solo.

En la figura a continuación se presenta los lineamientos discursivos de los opositores de la Resolución 99 desde la categoría temática Relación iglesia-estado.

Figura \#2

Relación iglesia-estado

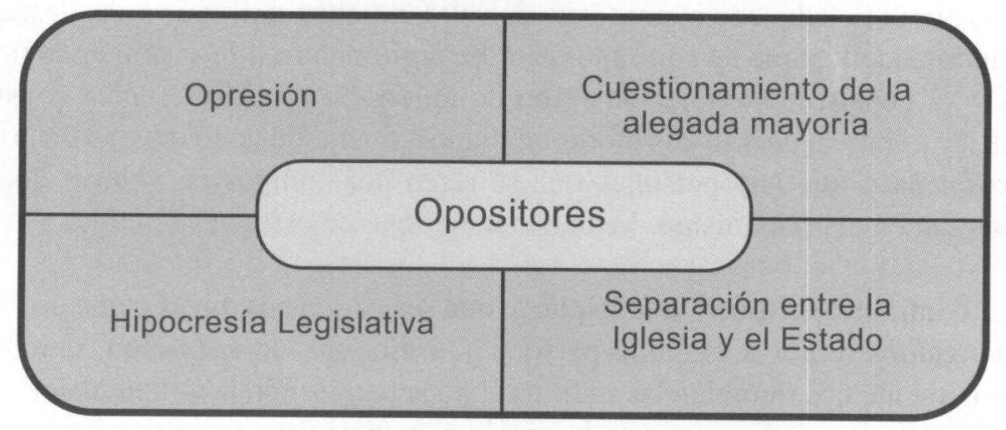

En el discurso de los opositores a la Resolución 99 hubo referencias constantes a los mecanismos de opresión que utiliza el Estado para subyugar las parejas homosexuales. Esta opresión fue comparada con eventos como el genocidio a los judíos y la inquisición, enjuiciando directamente a los favorecedores de la medida, al establecer que su aprobación podría tener efectos similares a los eventos antes mencionados. Hubo señalamientos en los que categorizaban a los legisladores como homofóbicos y a las iglesias de intolerantes. La opresión debía ser contrarrestada fomentando una educación dirigida a la equidad y ofreciéndole alternativas a todas las diversas familias para que tengan a su disposición los recursos necesarios para su pleno desarrollo y no penalizando la diversidad.

Se cuestionó la supuesta mayoría que alegaban tener sectores religiosos que apoyaron la medida y dejaron claro que aunque ese fuera el caso no justificaría la exclusión de los grupos minoritarios. Se intentó debilitar el argumento de que las mayorías, por el mero hecho de ser mayoría, deben tener el poder de imponer su voluntad al resto de la ciudadanía, más aun cuando eso implique el que se violenten derechos civiles. 
Se valoró también la importancia que tiene para varias personas la fe, sin embargo se hizo clara la postura en cuanto a la separación de Iglesia y Estado. Según esta visión, con el fin de respetar la libre determinación de cada cual de practicar o no una religión, no se deben imponer mediante ley preceptos religiosos. Organizaciones religiosas validaron la importancia de la separación de Iglesia y Estado, entendiendo que no se deben imponer ideas, aún cuando como cristianos las validen en su vida personal. Se apreció cómo a pesar de que algunos grupos religiosos defendieron que el matrimonio debe ser heterosexual, reconocieron que se le deben garantizar derechos a otro tipo de uniones. Esta posición se distanció por mucho de la visión fatalista expresada por las organizaciones religiosas favorecedoras de la medida. Veamos:

Creemos en la separación de Iglesia y Estado pues esta fórmula garantiza precisamente el no hacer de una doctrina denominacional la norma para los que puedan diferir. Nos preocupan inclusive aquellos y aquellas que puedan profesar otras religiones y personas agnósticas o ateas que pueden quedar afectadas por estas pretensiones de legislación y sobre quienes amerita nuestra consideración (Olmo, 2008, p.3).

Se expresó también que la aprobación de esta medida no respondería a un compromiso genuino con los valores religiosos, sino con las posibilidades de los legisladores de ser reelectos en las próximas elecciones. Se le atribuye así abiertamente a los legisladores falta de compromiso con la defensa constitucional. Se justifica de esta manera su apoyo a la medida en intereses particulares y no en el bien colectivo. Cabe señalar que este proceso se dio poco antes de las primarias electorales, lo cual pudo haber influido en el comportamiento de los legisladores.

Otra de las áreas estudiadas en el discurso de personas favorecedoras de la Resolución 99 fue en torno al tema de la masculinidad hegemónica. En la figura a continuación se presentan los lineamientos discursivos desde la categoría temática masculinidad hegemónica.

\section{Figura \#3}

\section{Masculinidad Hegemónica}




La masculinidad hegemónica implica el confinamiento de la diversidad sexual a la heterosexualidad. No obstante, el discurso de los sectores fundamentalistas no sólo restringe la sexualidad, sino que también reproduce la masculinidad hegemónica estableciendo así la heteronormatividad y los modos de opresión que le acompañan tales como la homofobia, el discrimen y la desigualdad. Bajo el predominio de esta pauta es que se obvia la diversidad.

El sostenimiento de la masculinidad hegemónica, a través de los códigos del lenguaje favorece al patriarcado. El patriarcado degrada a las mujeres subordinándolas ante los hombres. Igualmente, degrada a todos los hombres que no se ajusten a la heteronormatividad. El análisis crítico revela cómo los discursos de legisladores y legisladoras y de los grupos fundamentalistas de la sociedad puertorriqueña perpetúan el imaginario colectivo sobre los significados atribuidos a las personas lésbicas, gays, bisexuales, transexuales y transgénero (LGBTT). Véase el siguiente texto:

En contraste con esta comprobada realidad: que el matrimonio heterosexual monógamo propicia una mejor salud en términos generales, y una mejor salud sexual y reproductiva en particular, está la otra realidad: la promiscuidad heterosexual y la práctica de la homosexualidad producen serios problemas de salud con sus consecuentes altos costos de salud para el gobierno. Esta verdad es tan evidente como la anterior, así que solo unas pocas pruebas bastan... (Hernández, 2008, p.5).

En este texto se identifica la dicotomía entre dos realidades. Una realidad es "que el matrimonio heterosexual monógamo propicia una mejor salud". A esta realidad se le adjudica el adjetivo 'comprobada' para darle peso al argumento. Mientras que la otra realidad es que "la promiscuidad heterosexual y la práctica de la homosexualidad producen serios problemas de salud". En primer lugar, existen diversas realidades. Las dicotomías se construyen bajo un modo de conocer positivista. Por ejemplo, la dicotomía principal en este texto es heterosexualidad/homosexualidad. Se coloca a la primera en posición de superioridad. Igualmente, este discurso está cargado de estigma, puesto que indica que los homosexuales son enfermos y que son un costo o un gasto público que afecta el presupuesto gubernamental. Por el contrario, las personas LGBTT aportan pagando contribuciones y para esto si se les trata de igual manera. Prosigue el discurso desde el poder articulando:

¿Cuál es el plan de Dios para el matrimonio? Que sea formado por un hombre y una mujer: no por dos hombres o dos mujeres o cualquier otra combinación, sino por un hombre y una mujer. Las condiciones de complementarse en lo físico, en lo emocional, en lo intelectual y en lo espiritual no pueden lograrse completa 
y perfectamente en un matrimonio integrado por dos hombres o dos mujeres (Rolón, 2007, p. 3).

Se transmite el mensaje de que el plan de Dios es que el matrimonio sea formado por un hombre y una mujer. La intención es que el Estado acate dicho plan como lo hace la Iglesia. Se observa el rechazo claro hacia las uniones homosexuales y se dicta la pauta de la pareja heterosexual como la única que debe ser aprobada en el nombre de Dios.

El texto afirma sin fundamento alguno que "las condiciones de complementarse en lo físico, en lo emocional, en lo intelectual y en lo espiritual no pueden lograrse completa y perfectamente en un matrimonio integrado por dos hombres o dos mujeres." Las parejas gay o lésbicas no son como un matrimonio heterosexual: presentan dinámicas, fases, problemas y recursos específicos. Desde un enfoque holístico se visualiza al ser humano en sus diversas esferas, las físicas, intelectuales, psicológicas, sociales y espirituales. No obstante, el progreso de cada una de estas esferas depende del desarrollo humano de cada persona y no está circunscrito al tipo de unión. En la entrelínea se está diciendo que el matrimonio heterosexual es la unión completa, perfecta y funcional, mientras que todo lo que no es pareja heterosexual se ubica en lo incompleto, imperfecto y disfuncional porque según este discurso, la condición por excelencia para que una unión se complemente o se integre exitosamente es la heterosexualidad.

Los lineamientos discursivos desde la categoría temática masculinidad hegemónica también fue estudiada desde la perspectiva de las pessonas opositoras a la Resolución de 99.

Figura \#3

Masculinidad Hegemónica



Los textos en contra de la Resolución 99 constituyen los contradiscursos que deconstruyeron las premisas afirmadas por los grupos a favor de dicha medida. Analicemos a continuación los argumentos principales que se identificaron en los discursos de dichos grupos. El Presidente de Puerto Rico para Todos y Todas afirmó: 
El debate al que se enfrentan ahora los legisladores y los puertorriqueños en general, es si a las personas lesbianas, gay, bisexuales y transgéneros se les permitirá tener una vida en pareja estable o si la sociedad prefiere mantener a las parejas del mismo sexo y a sus hijos en la precariedad legal y la clandestinidad (Serrano, 2007, p.3).

Con este discurso se le dice a los legisladores(as) y al país que el debate es si se reconocen los derechos de todos(as) los ciudadanos(as), independientemente de la orientación sexual o si se continuará perpetuando la exclusión de derechos. Se cuestiona el trato hacia las personas LGBTT como ciudadanos(as) de segunda clase. Este discurso va dirigido a concienciar a la ciudadanía para que no se reproduzca el estigma hacia la diversidad sexual. A consecuencia del estigma muchas personas optan por ocultar (clandestinidad) su orientación sexual, ya que sufren la homofobia.

Hace referencia a las familias homoparentales que tienen niños y niñas que son desprotegidos por el Estado al excluir a las parejas del mismo sexo de derechos que beneficiarían el núcleo familiar.

\section{Reflexiones Finales}

La Resolución \#99 se puede considerar uno de los intentos más recientes de regular la sexualidad humana en función del sistema capitalista. Como proyecto de legislación, por parte del Estado, tuvo la intención de elevar el discrimen a rango constitucional. Las denominaciones religiosas fundamentalistas y la mayoría de los legisladores y legisladoras articularon el discurso del poder que le niega características positivas a los grupos subalternos. Este discurso tiene la finalidad de controlar la sexualidad y de excluir la diversidad. Contiene un marco heterosexista que no permite entender la diversidad y la inclusión. Se justifica la exclusión alegándose que en la sociedad puertorriqueña se continúa valorizando más la estructura matrimonial heterosexual monógama.

Los sectores que demonizan las sexualidades subalternas no mostraron en sus discursos comprender el reclamo de los sectores opositores a la medida, ya que cuestionaba la narrativa heterosexista. Esta incomprensión se entiende como uno de los factores que incide en el marcado rechazo de estos grupos a todas aquellas uniones familiares que no respondan a su visión de mundo. Los sectores fundamentalistas ven en el discurso de la resistencia un ataque y una amenaza. Este discurso deconstruye los aprendizajes que han adquirido en una sociedad heterosexista. Los cambios sociales hacia una mayor aceptación de la diversidad sexual, familiar y el empoderamiento de las mujeres representan un mundo heterosexista y patriarcal que se derrumba y que tienen que proteger. El discurso desde el poder sostiene a la masculinidad hegemónica como estructura, mientras el discurso de la resistencia refleja la masculinidad contestataria, la cual reta la normatividad. 
Esto reafirma los planteamientos hechos por Ramírez y García (2002) quienes estipulan que "en el análisis de la opresión, hacia las parejas del mismo sexo, se tiene que visualizar el acceso diferencial... al poder, el predominio de la masculinidad hegemónica y el homoerotismo como identidad de género subordinada y transgresora" (p.6). Igualmente, establecen que la masculinidad hegemónica constituye la heteronormatividad que mantiene al margen a las personas que no se ajustan a sus estándares; "la hegemonía es la supremacía social, el dominio en la organización del Estado y de la sociedad civil de un grupo que reclama e impone su predominio en las relaciones sociales y en la vida cultural. El grupo hegemónico se conserva en el poder manteniendo la dirección ideológica de la sociedad" (Ramírez y García, 2002, p.7). Esto implica que la sociedad en general internaliza las ideologías dominantes de la élite. Por tanto, las personas en su cotidianidad reproducen los arreglos sociales establecidos por el régimen ideológico.

En Puerto Rico la homofobia permanece como un prejuicio aceptado socialmente. Se concluye que el discurso desde el poder que manifestaron los sectores fundamentalistas estuvo cargado de homofobia. Este discurso estuvo fundamentado en el miedo, perpetuando ideas respecto a la homosexualidad como generadora de enfermedad. Su discurso fue sumamente estigmatizante catalogando a los homosexuales como enfermos físicos y mentales.

La participación ciudadana de los grupos opositores constituyó el ejercicio del poder de las personas oprimidas que articularon el contra-discurso restituyendo el placer a lo real (Foucault, 2007). El restablecimiento del placer a lo real rompe con modos de opresión como lo son la homofobia o el miedo al placer. Restituir el placer a lo real implica ver la existencia de relaciones sexuales entre parejas del mismo sexo sin invisibilizar o acallar su presencia en la sociedad puertorriqueña. El hecho de que existan grupos que hablen sobre la represión del sexo involucra acciones transgresoras.

La Resolución 99 fue una propuesta legislativa que evidenció cómo los dogmas religiosos pasan al Derecho. Esto se debe a que el conservadurismo religioso, como ideología, se filtró en el Estado por medio de sus representantes legislativos. Permitiendo que los dogmas religiosos se conviertan en ley y el pecado en crimen.

Entre las ideologías identificadas se destacan el patriarcado, la propiedad privada y el heterosexismo. Estas ideologías legitiman las relaciones de desigualdad entre gobernantes y gobernados/as. El discurso de los favorecedores de la Resolución 99 legitima las relaciones de desigualdad entre homosexuales y heterosexuales. El heterosexismo, transmitido a través del lenguaje, causa la segregación de la ciudadanía por orientación sexual. Esta ideología le da supremacía a los heterosexuales sobre los homosexuales, obligando a los últimos a vivir "como si" fueran heterosexuales. Se asume que la heterosexualidad es lo natural y normal, mientras que la homosexualidad es una desviación que debe ser corregida (Maroto, 2006). 
El conflicto que surge ante la Resolución 99 se debe a que las ideologías dominantes, en determinados momentos de la historia, son enfrentadas por movimientos contestatarios. Esto provoca que se creen conflictos entre los diversos grupos en la lucha por acceder a la igualdad de derechos. La Resolución 99 fue un intento fundamentalista de influenciar la política pública y el estado de derecho. La transcripción legislativa reveló discursos de representantes legislativos, que contenían los criterios del Estado para seleccionar lo que debe y lo que no debe ser política pública, que en este caso fue la regulación de la sexualidad de los grupos subalternos. Los legisladores y las legisladoras usaron estos criterios para tomar la decisión de aprobar la Resolución 99 en el Senado. Esto representa un reflejo de la clase que el Estado favorece y los intereses que representa.

En el discurso de las transcripciones legislativas se identificó que cuando los intereses de los diferentes sectores sociales entraron en conflicto, la mayoría de los legisladores y legisladoras favorecieron los de la clase dominante, argumentando que estos son los intereses que más le convienen a la sociedad. El discurso detrás de esta Resolución propende a la opresión y patologización de todas las uniones familiares no tradicionales. Reproduciendo la distinción entre relación sexual normal o anormal, familia funcional o disfuncional, sexualidad legal o ilícita, entre otras. De esta manera se perpetúa la dicotomización de la sociedad en grupos sociales opuestos.

Al elevar a rango constitucional el matrimonio heterosexual y al responsabilizar a las familias de los males sociales que nos aquejan, se ejerce el Bio-Poder en ambos polos, tanto en el poder disciplinario como en la regulación de la población. Mediante el poder disciplinario se castiga a las uniones familiares no tradicionales al minimizarlas como una clase de segunda. Es a través de la regulación de la población que se concretiza el poder para decidir qué tipo de uniones familiares tendrán el derecho de procrear, adoptar y/o criar a su prole, ejerciendo así el control sobre el nacimiento y los estilos de crianza. El discurso de la Resolución 99 no reconoce la diversidad familiar, lo cual no responde a la realidad puertorriqueña, ya que impone la represión hacia toda familia que no sea producto del matrimonio, como lo son las madres jefas de familia, abuelos y abuelas, tíos y tías de crianza, y las parejas heterosexuales no casadas.

En el discurso de los grupos a favor de la enmienda se promueve el imaginario de un solo tipo de familia. Está presente la premisa de que la familia se encuentra bajo ataque. Esto se debe a que en el discurso prevalece la noción de la familia tradicional/nuclear/burguesa como estructura hegemónica. Se cree que la familia tradicional está bajo ataque, porque existe resistencia al cambio y al reconocimiento de la diversidad familiar.

Los patrones sociales cambian. Las realidades actuales en Puerto Rico no son las mismas que las de décadas previas, las familias son dinámicas. Los grupos fundamentalistas insisten en enmarcar a la diversidad en un prototipo de familia aún cuando las estructuras familiares han ido cambiando con el pasar del tiempo. Igualmente, el discurso desde el 
poder está basado en la presunción de que la familia tradicional es la forma apropiada para la distribución de funciones tales como la crianza de la prole. El discurso de los grupos fundamentalistas contenía significados y entendidos referentes a la familia nuclear como algo natural y dado. De esta forma se equipara a la estructura de dicha familia con el resto de la naturaleza. Lo que llevó a los grupos fundamentalistas a establecer una dicotomía entre 'lo natural' y lo 'no natural', asumiéndolo como 'lo moral' y 'lo inmoral', respectivamente.

El estado de Derecho es un espacio de mediación de las relaciones sociales y es el mecanismo que el Estado utiliza para requerir el control de los cuerpos. De esta forma el Estado limita la autodeterminación de la ciudadanía. Por consiguiente, se reprime la diversidad sexual y se construyen las uniones ilícitas. La Resolución 99 desató discursos asociados al sexo y al control del mismo. El intento de enmendar la constitución reflejó la utilización del ámbito legal para controlar y definir cómo las personas deben relacionarse entre sí y qué tipo de familia deben constituir. 


\section{Referencias}

Chatterjee, Pranab. (1996) Appraches to the welfare state. United States: NASW Press.

Comisión Conjunta Permanente para la Revisión y Reforma del Código Civil de Puerto Rico de 1930 (2003). Propuestas de la Comisión sobre los Libros del Código Civil de Puerto Rico. San Juan, Puerto Rico.

Foucault, Michael (2007) Historia de la sexualidad: 1. La voluntad de saber. (13ra Ed.) México: siglo XXI editores, s.a. de c.v.

Foucault, Michael (2003) Historia de la sexualidad: 2. La inquietud de sí. (3ra reimpresión) Argentina: siglo XXI Editores, s.a. de c.v.

Hernández Ortiz, William (2008) Fraternidad Pentecostal de Puerto Rico. Ponencia presentada ante la Cámara de Representante, San Juan, P.R.

Lucca Irrizari, Nydia., Berrios Rivera, Reynaldo (2009) La investigación cualitativa: fundamentos, diseños y estrategias. Cataño, Puerto Rico: Ediciones SM

Maroto Sáez, Ángel Luis. (2006). Homosexualidad y Trabajo Social. España: Siglo XXI.

O'Brien, Carol-Anne (1999) Contested Territory: Sexualities and Social Work. In Chambon, Adrienne; Irving, Allan \& Epstein, Laura, (Ed.)Reading Foucault for Social Work. New York: Columbia University Press.

Olmo, Manuel (2008, febrero) Iglesia Episcopal Puertorriqueña Reacción: Resolución Concurrente del Senado 99. Ponencia presentada ante la Cámara de Representantes de Puerto Rico, San Juan, P.R.

Ramírez, Rafael L., García, Víctor I. (2002). Masculinidad hegemónica, sexualidad y transgresión. Centro Journal, 14 (1), 5-25.

Rolón, Wanda (2007) Movimiento Apostólico de Restauración: La senda Antigua. Ponencia presentada ante el Senado de Puerto Rico, San Juan, P.R.

Senado de Puerto Rico (2007). Resolución Concurrente del Senado Núm. 99 del 24 de abril de 2007. San Juan, Puerto Rico: Autor

Senado de Puerto Rico (2007, octubre) Transcripción de la discusión de la Resolución Concurrente del Senado Núm. 99, San Juan, P.R. 
Serrano, Pedro Julio (2007) Puerto Rico para tod@s. Ponencia presentada ante el Senado de Puerto Rico, San Juan, P.R.

Sociedad Puertorriqueña de Psiquiatría (2008). La Sociedad Contemporánea y el análisis a través de los conceptos de la Teoría de Sistema. Ponencia presentada ante la Comisión de lo Jurídico y Seguridad Pública de la Cámara de Representantes sobre la Resolución Concurrente del Senado Núm. 99. San Juan: Autor 
